\title{
sciendo
}

\section{Should Students Trust their Instructors in Statistics? Differences in PLS Path Modelling while using WarpPLS and R}

\author{
Elena DRUICĂ \\ University of Bucharest, Bucharest, Romania \\ elena.druica@faa.unibuc.ro \\ Zizi GOSCHIN \\ Bucharest University of Economic Studies, Bucharest, Romania \\ Institute of National Economy, Bucharest, Romania \\ zizi.goschin@csie.ase.ro
}

\begin{abstract}
A common problem with using different statistical packages for the same data and method is the risk of getting dissimilar results. While the reasons behind this outcome are often known and accepted, the negative consequences might be significant. In a teaching environment, usually involving toy models, with no practical implications, only a reputation risk is at stake. Nevertheless, students should be aware of such incongruities, their causes and possible solutions. Starting from these considerations, our paper addresses the differences that arise between $R$ and WarpPLS while applying the Partial Least Squares Path Modelling (PLS-PM) method. To this end we estimate a PLS-PM model for analysing health-positioning data, compare the results and explain how the two statistical packages differ and complement each other in an attempt to derive the best fit for the data.
\end{abstract}

Keywords: statistical packages, R, WarpPLS, SEM, health-positioning data.

\section{Introduction}

Nowadays there is a large supply of statistical software, differing in both the range of techniques they cover and in their reliability, as often debated in the literature (Keeling \& Pavur, 2007; McCullough, 1999; Odeh, Featherstone, \& Bergtold, 2010). Among the issues related to the choice of best statistical software to use, the problem of dissimilar results coming up when different statistical packages are applied to same data and method is not new among users.

Despite occasional slight differences, mainstream statistical software usually provides consistent results. Larger discrepancies can emerge between open - source and license based statistical packages, and there is a fierce debate regarding the reliability of the former compared to the latter. Open - source packages, such as R, are often preferred to license based ones given that the user has the possibility to check and/or develop the algorithm underling the computations (McCullough, 2010; Petras, Petrasova, Harmon, Meentemeyer, \& Mitasova, 2015; Weibel, Bleisch, \& Fisler, 2012; Yalta \& Yalta, 2010). A few journals, such as the Journal of Statistical Software, provide free source codes associated with the articles, enabling not only replications, but also adaptations (according to specific needs of other researchers) and further development of the software (Ertz, Rey, \& Joost, 2014). In opposition, most license - based statistical packages are viewed as mere "black boxes" for the users (Yalta \& Yalta, 2010). 
Consequences of the differences in estimation results vary with the importance of the problem under research. The least serious outcomes raise in a teaching environment, since normally all students use the same statistical software. Moreover, even if multiple packages are used, teaching involves toy models, with no practical implications, and with a clear emphasize on the method. Only a reputation risk in what statistical software usage is concerned is at stake. In a research context, ambiguities are prevented through usual journals' request of clear information regarding the manner in which the analysis is conducted (i.e. data, software identification, etc.). The most important consequences might emerge in a policymaking framework, in terms of potential misleading information driving less adequate or even entirely wrong decisions.

Advanced data analysts are aware not only of the problem, but very often of the reasons of these differences. Such discrepancies usually arise from rounding, truncation, imputation of missing data, or from the algorithm specifying either single or double precision. The computation methods could also differ, for instance the specific treatment of unbalanced data. Even small differences in implementing the same method can generate discrepancies. While minor differences in results, beyond the second decimal place, are of no consequence, major ones need proper examination, especially when incongruous definitions or formulae might be the object.

One recommended way of dealing with potentially misleading results attached to the same analysis is to double check the estimation using different statistical packages. In this paper we will focus on a PLS-PM model estimated via $\mathrm{R}$ and WarpPLS, in order to compare the results and explain how the two statistical packages differ and how they complement each other in our attempt to derive the final adequate conclusion.

The rest of the paper is organized as follows: next section presents the method along with a brief discussion of the capabilities of the packages involved in our comparison. Section 3 presents the data, the model, and the two means used to conduct the estimation. Section 4 presents the results, while the last section concludes, and sets implications.

\section{PLS - PM. A theoretical background}

Structural Equation Modelling is a popular multivariate technique for investigating latent phenomena, but its Partial Least Squares variant is less known, despite its advantages in modelling complex and multiple relationships between latent variables. PLS-PM provides latent variables using the partial least squares path modelling approach, the composites being determined as weighted combinations of initial variables, based on the algorithm developed by (Wold, 1975) and extended by (Lohmöller, 1989). The name "Partial Least Squares" indicates that parameters' estimation is based on an iterative least squares process, applied separately to each block of manifest variables forming a latent one. Thus, the estimation technique is partial, instead of involving the entire model at once.

Unlike the standard regression models analysing the unilateral influence of several predictors upon a dependent variable, PLS handles simultaneously multiple dependent variables and also allows for multicollinearity between explanatory variables. It combines features of factorial analysis with multiple regression (J. F. Hair, Sarstedt, Ringle, \& Mena, 2012). PLS can be used for regressing one or more dependent variables on a set of predictors, and also as a path model, identifying both causal paths among predictors and the ones linking predictors to dependent variables. PLS path model has two components: a structural (inner) model that displays the relationships (paths) between the latent variables and a 
measurement (outer) model that shows the relationships between the latent variables and the manifest ones (J. Hair, Hult, Ringle, \& Sarstedt, 2013). The latent variables are endogenous if influenced by at least one other latent construct in the model, else they are exogenous. The measurement model reflects causality relations: the exogenous latent constructs represent unobservable dimensions such as perceptions, preferences and judgments that "cause" the manifest variables, i.e. determine the behaviours captured by these variables. In the structural model the exogenous latent variables became causes for the endogenous latent variables.

The goodness-of-fit statistics for the PLS-PM are based on the deviations of theoretical values provided by the model from the observed values of manifest variables or approximate values in case of latent variables. Therefore, the quality of the model is assessed with various non-parametric criteria, employing bootstrapping procedures. Measurement models are evaluated based on composite reliability; indicator reliability; discriminant validity and variance extracted. Structural models are evaluated with determination coefficients, size and significance of path coefficients, and effect sizes (J. Hair et al., 2013).

Composite reliability coefficients should range between 0.60 and 0.70 in exploratory studies, else need to be higher (J. Hair et al., 2013). The variance extracted (how much is a manifest variable positively correlated with alternative measures of the same construct) is indicated by the external loadings of the indicators and the Average Variance Extracted - AVE. which should be above 0.50 . High external loadings (at least 0.708 ) in a latent variable show that the manifest variables relate well with the phenomenon captured by the respective construct, therefore indicator reliability is achieved. The discriminant validity verifies if a construct is unique and wholly distinct from the others. This implies that the square root of the AVE coefficients of each construct is higher than all (Pearson) correlations between the other latent constructs (Fornell and Larcker criterion).

PLS is also known as "composite-based SEM", in opposition to "covariance-based SEM," included in mainstream statistic software packages. The former is considered most useful for prediction or exploratory modelling (and less appropriate as an interpretive tool), while the latter is better for confirmatory modelling (Tobias R. D., 1997).

PLS brings multiple advantages: it allows multiple dependent (response) variables; accepts multicollinearity among predictors; handles missing data; works well even if the number of observations is low given the number of variables; creates independent composites using cross-products that involve the response variables. The latter can also be a disadvantage, since makes more difficult to interpret the loadings, given that it no longer reflects covariances among the manifest variables, as in common factor analysis (Garson, 2014).

Specialised software packages for PLS-PM include WarpPLS, SmartPLS, PLSGraph, NEUSREL, ADANCO, etc., while other general software packages, such as R, SAS and Stata allow the use of special source codes to perform PLS-PM.

\section{Data, model and estimation}

Our sample consists of 195 respondents, students of the University of Bucharest. The questionnaire was developed based on shortened versions of several validated scales, as follows. To measure stress management, social support and life appreciation, we used specific items from the Short-Form Adolescent Health Promotion Scale (Chen, Lai, Chen, \& Gaete, 2014). Self-control was measured using three items of the Brief Self-Control Scale 
(Tangney, Baumeister, \& Boone, 2004), for future orientation we used three of the items of the Short-Term Future Orientation Scale (Antonides, de Groot, \& van Raaij, 2011). To measure deliberative thinking we used two items of the Unified Scale to Assess Individual Differences in Intuition and Deliberation (Pachur \& Spaar, 2015). Other researches also implemented shortened versions of these scales (Strömbäck, Lind, Skagerlund, Västfjäll, \& Tinghög, 2017) and confirmed their psychometric properties. Table 1 presents the latent variables along with their corresponding measurement items.

Table 1. Latent variables measurement

\begin{tabular}{|c|c|}
\hline Latent variable & Measurement items \\
\hline \multirow{3}{*}{$\begin{array}{l}\text { Social Support } \\
\text { (Chen et al., 2014) }\end{array}$} & I speak up \& share my feelings with others. \\
\hline & I care about other people.s[s] \\
\hline & I talk about my concerns with others sisp: \\
\hline \multirow{8}{*}{$\begin{array}{l}\text { Life Appreciation } \\
\text { (Chen et al., 2014) }\end{array}$} & Make an effort to like myself \\
\hline & Make an effort to feel happy and content \\
\hline & I usually think positively \\
\hline & Make an effort to understand my strengths, weaknesses, and accept them \\
\hline & Make an attempt to correct my defects \\
\hline & Make an effort to know what's important for me \\
\hline & Make an effort to feel interesting and challenged every day \\
\hline & Make an effort to believe that my life has purpose. \\
\hline \multirow{3}{*}{$\begin{array}{l}\text { Self Control } \\
\text { (Tangney et al., 2004) }\end{array}$} & I get distracted easily \\
\hline & I do things that feel good at the moment, but regret later on \\
\hline & I often act without thinking through all the alternatives \\
\hline \multirow{3}{*}{$\begin{array}{l}\text { Future Orientation } \\
\text { (Antonides et al., 2011) }\end{array}$} & I only focus on the short term \\
\hline & The future will take care of itself \\
\hline & I live more for the day of today than for the day of tomorrow. \\
\hline \multirow{2}{*}{$\begin{array}{l}\text { Deliberative Thinking } \\
\text { (Pachur \& Spaar, 2015) }\end{array}$} & Developing a clear plan is very important to me. \\
\hline & I like to analyze problems. \\
\hline \multirow{2}{*}{$\begin{array}{l}\text { Stress Management } \\
\text { (Chen et al., 2014) }\end{array}$} & Make an effort to determine the source of my stress \\
\hline & Make an effort to watch my mood changes \\
\hline
\end{tabular}

Model and estimation. Our model estimates the level of stress management, as a function of age, self-control, future (short-term) orientation and deliberative thinking. Besides inquiring into the relationships between the outcome variable and its predictors, we explore two potential mechanisms, described as mediators: life appreciation and social support. Age, and the level of deliberative thinking predict social support. Life appreciation is predicted by age, deliberative thinking, self-control and future orientation.

Although our model is feasible in terms of theoretical underpinning, it is not meant to provide any contribution in terms of empirical results: it is only a toy model, used to illustrate similarities and differences between WarpPLS and R. We estimated the model in two different settings. On the one side, we use the "plmps" package available in the open source $\mathrm{R}$ software, and on the other side we used WarpPLS. We reported the main results as usually in a PLS-PM analysis, then compared the results. In terms of statistical significance, we choose to conduct a testing based on a bootstrapping procedure with 999 resampling. 


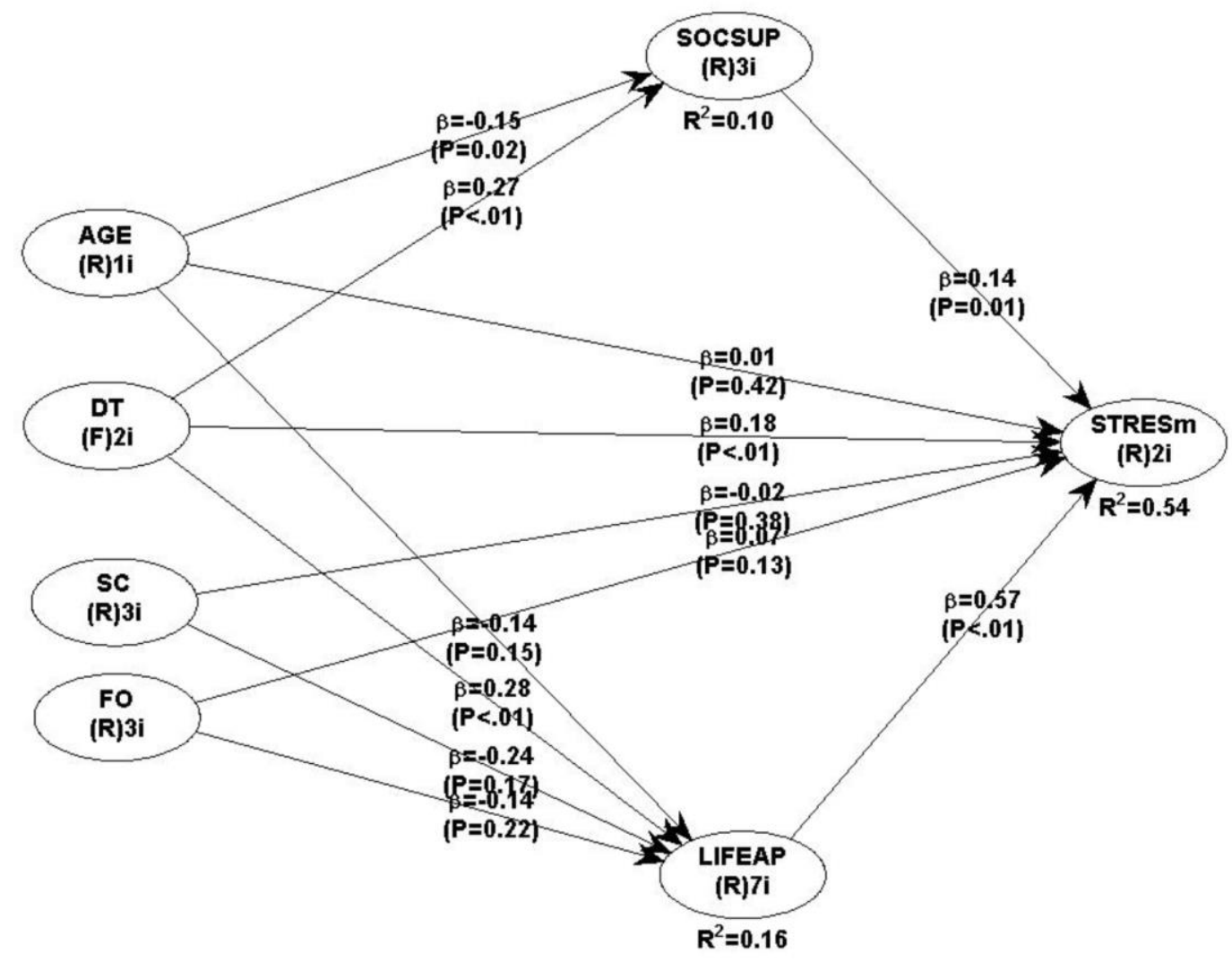

Figure 1: The model along with the estimated path coefficients

The results are presented in Figure 1, and in the tables included in the next section.

\section{Results and discussions}

Our paper presents two parallel estimations of the same variance - based structural model: one of the estimations is conducted in WarpPLS, and the other one in R, using the "plspm" package. We used a real dataset comprising 195 students, 21 manifest variables that ended up in 7 constructs. To validate the results, we used bootstrapping with 999 resampling (WarpPLS) and 1000 resampling (R). The algorithm converges in 4 iteration for the $R$ estimation, and in 7 iterations for the WarpPLS estimation. In both cases, the outer model was estimated using PLS regression, while in case of WarpPLS we allowed the inner algorithm to capture potential non - linear relationships.

\section{The outer (measurement) model}

This part of the model provides information regarding the convergent and the discriminant validity of the measurement. The internal consistency is measured using Cronbach's Alpha (Cronbach, 1951; Kuder \& Richardson, 1937) and the DG rho composite reliability index (Tenenhaus et al., 2005). Table 2 summarizes the first two indices along with their recommended (theoretical) values of minimum 0.7 (Nunnally \& Bernstein, 1994), but it is also acceptable if only one of them fulfils this criterion (Kock \& Lynn, 2012). 
Table 2: Composite reliability

\begin{tabular}{|l|l|l|l|l|}
\hline \multicolumn{1}{|c|}{ Measure } & $\begin{array}{c}\text { Cronbach's Alpha } \\
(>\mathbf{0 . 7 )}\end{array}$ & \multicolumn{2}{c|}{$\begin{array}{l}\text { Composite reliability index } \\
(>\mathbf{0 . 7 )}\end{array}$} \\
\hline Software & WarpPLS & $\mathbf{R}$ & WarpPLS & R \\
\hline Social support & 0.742 & 0.742 & 0.853 & 0.853 \\
\hline Life Appreciation & 0.899 & 0.894 & 0.921 & 0.916 \\
\hline Self Control & 0.715 & 0.715 & 0.841 & 0.841 \\
\hline Future Orientation & 0.713 & 0.713 & 0.839 & 0.839 \\
\hline Deliberative Thinking & 0.664 & 0.664 & 0.856 & 0.856 \\
\hline Stress Management & 0.766 & 0.766 & 0.895 & 0.895 \\
\hline
\end{tabular}

Source: Authors' own research

The results displayed in Table 2 are barely different in case of "Life appreciation", but the differences are very small. Small differences are recorded in case of AVE (Table 2), but they are also very small: the larger one is also attached to "Life appreciation", from 0.625 in WarpPLS to 0.578 in R.

Cronbach's Alpha and the DG rho are both measures of internal consistency only if the scale is unidimensional. An important indication of block unidimensionality, the eigenvalues presented in Table 3, are not available in WarpPLS although they play an essential role: if the first eigenvalue is higher than 1 , but the second is lower, the unidimensionality condition is fulfilled (Tenenhaus et al., 2005). Otherwise, both Cronbach's Alpha and the DG rho are only indication of the extent to which the measurement is consistent in repeated measures, but not an indication internal reliability, or homogeneity (Sijtsma, 2009). Eigenvalues availability is in particular important in case of latent variables comprising of a larger number of items, as "Life appreciation" in our case, where the possibility of more than one-dimension increases.

Average variance extracted (AVE) provides information regarding the percentage of variance of the data explained by the latent variable. The discriminant validity of the measurement is achieved in our model through large AVE (Table 3).

Table 3: Average variance extracted and block unidimensionality

\begin{tabular}{|l|l|l|l|l|}
\hline \multicolumn{1}{|c|}{ Measure } & \multicolumn{2}{c|}{$\begin{array}{c}\text { AVE } \\
(>\mathbf{0 . 5})\end{array}$} & \multicolumn{2}{c|}{$\begin{array}{c}\text { Eigenvalue } \\
\mathbf{1}^{\text {st }}\end{array}$ 2 $^{\text {nd }}$} \\
\hline Software & WarpPLS & R & WarpPLS & R \\
\hline Social support & 0.660 & 0.658 & NA & $1.98 / 0.602$ \\
\hline Life Appreciation & 0.625 & 0.578 & NA & $4.64 / 0.875$ \\
\hline Self Control & 0.639 & 0.634 & NA & $1.92 / 0.683$ \\
\hline Future Orientation & 0.636 & 0.635 & NA & $1.91 / 0.591$ \\
\hline Deliberative Thinking & 0.749 & 0.743 & NA & $1.50 / 0.503$ \\
\hline Stress Management & 0.811 & 0.811 & NA & $1.62 / 0.379$ \\
\hline
\end{tabular}

Source: Authors' own research

The discriminant validity of a construct means that it is strongly related to the variables included in its composition ((J. Hair et al., 2013) and it is measured in two different ways. The combined loadings and cross loadings provided in Warp are presented in Table 4, while R supplies the results presented in Table 5. In both tables, the square roots of the AVEs on the main diagonal are well above the off-diagonal values, and the latter are below 0.8 , as required in literature. 
Table 4. Combined loadings and cross loadings - WarpPLS

\begin{tabular}{|l|l|l|l|l|l|l|}
\hline Results in WarpPLS & SC & FO & DT & SOCSUP & LIFEAPP & STRESm \\
\hline SC1 & $\mathbf{0 . 7 0 3}$ & -0.148 & -0.142 & 0.011 & -0.156 & 0.222 \\
\hline SC2 & $\mathbf{0 . 8 3 6}$ & 0.006 & 0.074 & 0.022 & -0.028 & -0.038 \\
\hline SC3 & $\mathbf{0 . 8 5 1}$ & 0.117 & 0.045 & -0.031 & 0.156 & -0.146 \\
\hline F01 & -0.038 & $\mathbf{0 . 7 8 3}$ & 0.101 & 0.037 & -0.002 & -0.095 \\
\hline F02 & 0.084 & $\mathbf{0 . 8 2 2}$ & -0.056 & -0.100 & -0.016 & -0.009 \\
\hline F03 & -0.050 & $\mathbf{0 . 7 8 6}$ & -0.042 & 0.068 & 0.019 & 0.105 \\
\hline DT1 & 0.013 & -0.010 & $\mathbf{0 . 8 6 5}$ & 0.092 & -0.176 & 0.033 \\
\hline DT2 & -0.013 & 0.010 & $\mathbf{0 . 8 6 5}$ & -0.092 & 0.176 & -0.033 \\
\hline SocSup1 & -0.163 & 0.077 & -0.030 & $\mathbf{0 . 8 3 4}$ & -0.049 & 0.037 \\
\hline SocSup2 & -0.028 & -0.036 & 0.020 & $\mathbf{0 . 7 5 7}$ & 0.039 & 0.139 \\
\hline SocSup3 & 0.186 & -0.044 & 0.011 & $\mathbf{0 . 8 4 5}$ & 0.013 & -0.161 \\
\hline LifeApp1 & 0.054 & 0.035 & -0.129 & 0.026 & $\mathbf{0 . 8 4 7}$ & -0.115 \\
\hline LifeApp2 & -0.090 & 0.072 & 0.079 & 0.045 & $\mathbf{0 . 8 3 4}$ & -0.088 \\
\hline LifeApp3 & -0.082 & 0.025 & 0.225 & -0.002 & $\mathbf{0 . 7 0 2}$ & 0.091 \\
\hline LifeApp4 & 0.029 & -0.139 & -0.026 & -0.222 & $\mathbf{0 . 8 4 6}$ & 0.076 \\
\hline LifeApp5 & -0.059 & 0.153 & 0.085 & 0.116 & $\mathbf{0 . 7 5 0}$ & 0.017 \\
\hline LifeApp6 & 0.071 & -0.041 & 0.009 & -0.069 & $\mathbf{0 . 8 0 3}$ & 0.123 \\
\hline LifeApp7 & 0.068 & -0.097 & -0.222 & 0.132 & $\mathbf{0 . 7 4 0}$ & -0.093 \\
\hline StrMan2 & 0.011 & -0.010 & 0.018 & 0.092 & -0.052 & $\mathbf{0 . 9 0 0}$ \\
\hline StrMan3 & -0.011 & 0.010 & -0.018 & -0.092 & 0.052 & $\mathbf{0 . 9 0 0}$ \\
\hline
\end{tabular}

Source: Authors' own research

Although there are several differences between the results in Table 4 and 5 , the similarity is evident. Two notable exceptions are worthy to be mentioned, however: SC1 and LifeApp2 are both loading higher than 0.7 in WarpPLS, as an indication that they should be kept as part of their corresponding latent variables. What the $\mathrm{R}$ output shows instead is that the same loadings are lower than the threshold values, thus they should be dropped from the analysis (Sanchez, 2013). If followed, this recommendation has important implications on the structure of the latent variables used in this, or any other analysis and ends up in challenges for the final model pursued to be estimated. We randomly varied the number of bootstrapping repetitions from 100 to 1000, and the same differences occur.

Table 5. Combined loadings and cross loadings - $\mathbf{R}$

\begin{tabular}{|l|l|l|l|l|l|l|}
\hline Results in R & SC & FO & DT & SOCSUP & LIFEAPP & STRESm \\
\hline SC1 & $\mathbf{0 . 6 8 3}$ & 0.136 & -0.110 & 0.022 & -0.097 & -0.029 \\
\hline SC2 & $\mathbf{0 . 8 8 6}$ & 0.238 & -0.028 & 0.001 & -0.128 & -0.078 \\
\hline SC3 & $\mathbf{0 . 8 0 6}$ & 0.327 & -0.074 & -0.039 & -0.049 & -0.073 \\
\hline F01 & 0.225 & $\mathbf{0 . 7 8 9}$ & -0.087 & -0.127 & -0.081 & -0.012 \\
\hline FO2 & 0.294 & $\mathbf{0 . 7 9 7}$ & -0.187 & -0.248 & -0.132 & -0.069 \\
\hline F03 & 0.181 & $\mathbf{0 . 8 0 4}$ & -0.079 & -0.054 & 0.044 & 0.117 \\
\hline DT1 & -0.058 & -0.143 & $\mathbf{0 . 8 0 7}$ & 0.217 & 0.129 & 0.249 \\
\hline DT2 & -0.075 & -0.113 & $\mathbf{0 . 9 1 3}$ & 0.180 & 0.332 & 0.349 \\
\hline SocSup1 & -0.111 & -0.134 & 0.181 & $\mathbf{0 . 8 2 5}$ & 0.328 & 0.353 \\
\hline SocSup2 & -0.043 & -0.154 & 0.213 & $\mathbf{0 . 7 9 5}$ & 0.394 & 0.399 \\
\hline SocSup3 & 0.165 & -0.131 & 0.145 & $\mathbf{0 . 8 1 4}$ & 0.233 & 0.219 \\
\hline LifeApp1 & -0.031 & -0.008 & 0.124 & 0.300 & $\mathbf{0 . 7 8 6}$ & 0.534 \\
\hline LifeApp2 & -0.223 & -0.007 & 0.116 & 0.302 & $\mathbf{0 . 5 4 6}$ & 0.294 \\
\hline LifeApp3 & -0.139 & -0.051 & 0.264 & 0.337 & $\mathbf{0 . 8 6 0}$ & 0.560 \\
\hline LifeApp4 & -0.120 & -0.063 & 0.339 & 0.332 & $\mathbf{0 . 7 6 3}$ & 0.541 \\
\hline
\end{tabular}




\begin{tabular}{|l|l|l|l|l|l|l|}
\hline Results in R & SC & FO & DT & SOCSUP & LIFEAPP & STRESm \\
\hline LifeApp5 & -0.094 & -0.132 & 0.206 & 0.201 & $\mathbf{0 . 8 3 4}$ & 0.565 \\
\hline LifeApp6 & -0.086 & 0.007 & 0.271 & 0.344 & $\mathbf{0 . 7 7 3}$ & 0.554 \\
\hline LifeApp7 & -0.031 & -0.051 & 0.241 & 0.298 & $\mathbf{0 . 7 8 3}$ & 0.587 \\
\hline StrMan1 & -0.056 & -0.004 & 0.330 & 0.421 & 0.597 & $\mathbf{0 . 9 0 1}$ \\
\hline StrMan2 & -0.085 & 0.041 & 0.308 & 0.311 & 0.638 & $\mathbf{0 . 8 9 9}$ \\
\hline
\end{tabular}

Source: Authors' own research

WarpPLS also provides the correlations among latent variables with square roots of AVEs (Table 6), while this information is not available in $R$.

Table 6: Correlations among latent variables with square roots of AVEs (WarpPLS)

\begin{tabular}{|l|l|l|l|l|l|l|}
\hline WarpPLS & $\begin{array}{l}\text { Self } \\
\text { Control }\end{array}$ & $\begin{array}{l}\text { Future } \\
\text { Orientation }\end{array}$ & $\begin{array}{l}\text { Deliberative } \\
\text { Thinking }\end{array}$ & $\begin{array}{l}\text { Social } \\
\text { Support }\end{array}$ & $\begin{array}{l}\text { Life } \\
\text { Appreciation }\end{array}$ & $\begin{array}{l}\text { Stress } \\
\text { Management }\end{array}$ \\
\hline Self Control & $\mathbf{0 . 8 0 0}$ & 0.303 & -0.084 & 0.004 & -0.088 & -0.077 \\
\hline $\begin{array}{l}\text { Future } \\
\text { Orientation }\end{array}$ & & $\mathbf{0 . 7 9 7}$ & -0.153 & -0.179 & -0.073 & 0.013 \\
\hline $\begin{array}{l}\text { Deliberative } \\
\text { Thinking }\end{array}$ & & & & & & \\
\hline Social Support & & & $\mathbf{0 . 8 6 5}$ & 0.225 & 0.251 & 0.346 \\
\hline Life Appreciation & & & & $\mathbf{0 . 8 1 3}$ & 0.375 & 0.394 \\
\hline $\begin{array}{l}\text { Stress } \\
\text { Management }\end{array}$ & & & & & $\mathbf{0 . 7 9 1}$ & 0.687 \\
\hline
\end{tabular}

Source: Authors' own research

Although R does not compute the square roots of AVEs, the correlations among latent variables are still available. They can be found in Table 7, where the authors calculated the values on the main diagonal using the information about AVEs presented in Table 3 . There are small differences between the results in WarpPLS and R in this case, like for example the case for "Life Appreciation" (sq. rts. of AVE = 0.791 in WarpPLS and 0.769 in R), but they do not impact the conclusion. Other measures of discriminant validity are available, but none of them is provided in either "plspm" R package, or WarpPLS.

Table 7: Correlations among latent variables with square roots of AVEs (R)

\begin{tabular}{|l|l|l|l|l|l|l|}
\hline $\mathbf{R}$ & $\begin{array}{l}\text { Self } \\
\text { Control }\end{array}$ & $\begin{array}{l}\text { Future } \\
\text { Orientation }\end{array}$ & $\begin{array}{l}\text { Deliberative } \\
\text { Thinking }\end{array}$ & $\begin{array}{l}\text { Social } \\
\text { Support }\end{array}$ & $\begin{array}{l}\text { Life } \\
\text { Appreciation }\end{array}$ & $\begin{array}{l}\text { Stress } \\
\text { Management }\end{array}$ \\
\hline Self Control & $\mathbf{0 . 7 9 6}$ & 0.291 & -0.079 & -0.004 & -0.129 & -0.077 \\
\hline $\begin{array}{l}\text { Future } \\
\text { Orientation }\end{array}$ & & $\mathbf{0 . 7 9 7}$ & -0.149 & -0.182 & -0.063 & 0.013 \\
\hline $\begin{array}{l}\text { Deliberative } \\
\text { Thinking }\end{array}$ & & & $\mathbf{0 . 8 6 2}$ & 0.225 & 0.303 & 0.354 \\
\hline Social Support & & & & $\mathbf{0 . 8 1 1}$ & 0.389 & 0.407 \\
\hline $\begin{array}{l}\text { Life } \\
\text { Appreciation }\end{array}$ & & & & & & 0.769 \\
\hline $\begin{array}{l}\text { Stress } \\
\text { Management }\end{array}$ & & & & & & 0.685 \\
\hline
\end{tabular}

Source: Authors' own research

The inner (structural) model. Overall, the model has a Tenenhaus goodness of fit of 0.388 , or 0.441 , depending on the software package used for estimation: $\mathrm{R}$ and respectively 
WarPLS. While the two values are not totally different, their interpretation differs in the view of the software developers. The developer of the $\mathrm{R}$ package required a Tenenhaus goodness of fit to be higher than 0.7 (Sanchez, 2013), while the accepted intervals in WarpPLS are: small if $>=0.1$, medium if $>=0.25$, large if $>=0.36$. Consequently, we found conflicted results, in the sense that the model is good according to WarpPLS, but not so reliable according to $\mathrm{R}$. On another side, there seems to be an agreement not only on the limitations of the Tenenhaus index as a measure of goodness of fit, but also an ongoing debate regarding the appropriate measurement that captures best the quality of the model (Evermann \& Tate, 2016; Sarstedt, Hair, Ringle, Thiele, \& Gudergan, 2016; Shmueli, Ray, Velasquez Estrada, \& Chatla, 2016).

Tables 8 and 9 present the estimated coefficients of the model in terms of direct, indirect and total effects. Both estimations are made based on bootstrapping procedures: in WarpPLS the maximum number of resampling is 999, while in $\mathrm{R}$ we allowed for 1000 . Since bootstrapping is a random procedure, we expected moderate differences among coefficients, and our expectation is confirmed. However, the statistical significance of the relationships in case of direct effects is the same regardless the packages used for estimation.

When comparing the total effects, the differences are more salient. Some of the estimated coefficients describe statistically insignificant relationships, so the differences have no impact in terms of interpretation. It is the case for age, self-control and future orientation. However, deliberative thinking appears to have different coefficients both in terms of indirect effect, and total effect, being meanwhile statistically significant.

Table 8. Estimated coefficients in WarpPLS

\begin{tabular}{|c|c|c|c|c|c|}
\hline \multirow{2}{*}{$\begin{array}{l}\text { Results in } \\
\text { WarpPLS }\end{array}$} & \multicolumn{3}{|c|}{ Direct effects } & \multirow{2}{*}{$\begin{array}{c}\text { Indirect effects } \\
\text { on Stress } \\
\text { management }\end{array}$} & \multirow{2}{*}{$\begin{array}{c}\text { Total effects on } \\
\text { Stress } \\
\text { management }\end{array}$} \\
\hline & $\begin{array}{l}\text { Social } \\
\text { support }\end{array}$ & $\begin{array}{c}\text { Life } \\
\text { Appreciation }\end{array}$ & $\begin{array}{c}\text { Stress } \\
\text { Management }\end{array}$ & & \\
\hline Social support & - & - & $\begin{array}{l}0.143^{*} \\
(0.014)\end{array}$ & - & $\begin{array}{l}0.143^{*} \\
(0.014)\end{array}$ \\
\hline $\begin{array}{l}\text { Life } \\
\text { Appreciation }\end{array}$ & - & - & $\begin{array}{l}0.571^{* * *} \\
(<0.001)\end{array}$ & - & $\begin{array}{l}0.571^{* * *} \\
(<0.001)\end{array}$ \\
\hline Self Control & - & $\begin{array}{l}-0.237 \\
(0.173)\end{array}$ & $\begin{array}{l}-0.020 \\
(0.383)\end{array}$ & $\begin{array}{l}-0.135 \\
(0.172)\end{array}$ & $\begin{array}{l}-0.155 \\
(0.153)\end{array}$ \\
\hline $\begin{array}{l}\text { Future } \\
\text { Orientation }\end{array}$ & - & $\begin{array}{l}-0.144 \\
(0.221)\end{array}$ & $\begin{array}{l}0.065 \\
(0.134)\end{array}$ & $\begin{array}{l}-0.082 \\
(0.219)\end{array}$ & $\begin{array}{l}-0.016 \\
(0.451)\end{array}$ \\
\hline $\begin{array}{l}\text { Deliberative } \\
\text { Thinking }\end{array}$ & $\begin{array}{l}0.273^{* * *} \\
(<0.001)\end{array}$ & $\begin{array}{l}0.279^{* * *} \\
(<0.001)\end{array}$ & $\begin{array}{l}0.184^{* *} \\
(0.002)\end{array}$ & $\begin{array}{l}0.199^{* * *} \\
(<0.001)\end{array}$ & $\begin{array}{l}0.383^{* * *} \\
(<0.001)\end{array}$ \\
\hline Age & $\begin{array}{l}-0.154^{*} \\
(0.025)\end{array}$ & $\begin{array}{l}-0.140 \\
(0.147)\end{array}$ & $\begin{array}{l}0.012 \\
(0.425)\end{array}$ & $\begin{array}{l}-0.102^{*} \\
(0.01)\end{array}$ & $\begin{array}{l}-0.090 \\
(0.200)\end{array}$ \\
\hline $\begin{array}{l}\text { R2/ Adjusted } \\
\text { R2 }\end{array}$ & $9.6 \% / 8.6 \%$ & $16.4 \% / 14.7 \%$ & $53.9 \% / 52.4 \%$ & - & - \\
\hline
\end{tabular}

* Standard errors in parentheses

Source: Authors' own research

An important observation is that, although $\mathrm{R}$ provides the decomposition of the total effect in direct and indirect effects, there is no explicit calculation of the standard error of the indirect effects and therefore their statistical significance cannot be assessed based on the provided output. The problem is important, given the fact that although the indirect effect is calculated as the product of two paths coefficients, there is no warranty that two statistically significant relationships will eventually lead to a statistically significant indirect effect.

One important detail to be mentioned is that these similar results were obtained by 
having preserved similar structures of the latent constructs, despite the results in Table 5 suggesting that two items (SC1 and LifeApp2) should be dropped.

Table 9. Estimated coefficients in $\mathbf{R}$

\begin{tabular}{|c|c|c|c|c|c|}
\hline \multirow[b]{2}{*}{ Results in $R$} & \multicolumn{3}{|c|}{ Direct effects } & \multirow{2}{*}{$\begin{array}{c}\text { Indirect } \\
\text { effects on } \\
\text { Stress } \\
\text { Management }\end{array}$} & \multirow{2}{*}{$\begin{array}{c}\text { Total effects } \\
\text { on } \\
\text { Stress } \\
\text { Management }\end{array}$} \\
\hline & $\begin{array}{c}\text { Social } \\
\text { support }\end{array}$ & $\begin{array}{c}\text { Life } \\
\text { Appreciation }\end{array}$ & $\begin{array}{c}\text { Stress } \\
\text { Management }\end{array}$ & & \\
\hline Social support & - & - & $\begin{array}{l}0.160^{* *} \\
(0.067)\end{array}$ & - & $\begin{array}{l}0.160^{* *} \\
(0.067)\end{array}$ \\
\hline $\begin{array}{l}\text { Life } \\
\text { Appreciation }\end{array}$ & - & - & $\begin{array}{l}0.576^{* * *} \\
(0.062)\end{array}$ & - & $\begin{array}{l}0.576^{* * *} \\
(0.062)\end{array}$ \\
\hline Self Control & - & $\begin{array}{l}-0.102 \\
(0.107)\end{array}$ & $\begin{array}{l}-0.009 \\
(0.062)\end{array}$ & -0.065 & $\begin{array}{l}-0.068 \\
(0.093)\end{array}$ \\
\hline $\begin{array}{l}\text { Future } \\
\text { Orientation }\end{array}$ & - & $\begin{array}{l}-0.043 \\
(0.151)\end{array}$ & $\begin{array}{l}0.083 \\
(0.082)\end{array}$ & 0.004 & $\begin{array}{l}0.057 \\
(0.141)\end{array}$ \\
\hline $\begin{array}{l}\text { Deliberative } \\
\text { Thinking }\end{array}$ & $\begin{array}{l}0.246^{* * *} \\
(0.084)\end{array}$ & $\begin{array}{l}0.293^{* * *} \\
(0.072)\end{array}$ & $\begin{array}{l}0.153^{* *} \\
(0.058)\end{array}$ & 0.212 & $\begin{array}{l}0.361^{* * *} \\
(0.075)\end{array}$ \\
\hline Age & $\begin{array}{l}-0.126 \\
(0.068)\end{array}$ & $\begin{array}{l}-0.055 \\
(0.061)\end{array}$ & $\begin{array}{l}0.018 \\
(0.044)\end{array}$ & -0.046 & $\begin{array}{l}-0.033 \\
(0.060)\end{array}$ \\
\hline $\begin{array}{l}\text { R2: Original/ } \\
\text { Mean.boot }\end{array}$ & $6.55 \% / 7.95 \%$ & $10.49 \% / 15.45 \%$ & $52.26 \% / 53.55 \%$ & - & - \\
\hline
\end{tabular}

* Standard errors in parentheses

Source: Authors' own research

Effect sizes. Important information regards the effect sizes presented in Table 9. If the analysis is conducted in $\mathrm{R}$, those relationships found statistically significant will guide potential practical implications. The clear limit of this approach is that if the contribution of a certain predictor in explaining variance in the predicted outcome is not high enough, even for a statistically significant relationship the intervention is useless. Measuring effect sizes helps the analyst to identify the relationships that deserve attention and investment. Effect sizes measure, in absolute terms, a predictor's contribution to $\mathrm{R}^{2}$ of the endogenous dependent variable. Effect sizes' classes are: large (over 0.35$)$, medium (0.15-0.34) or small (0.02-0.14), while under 0.02, effects sizes are ineffective for practical interventions (Cohen, 1988; Kock, 2014). Effect sizes are unavailable in R, "plspm" package.

Table 9. Effect sizes for direct effects

\begin{tabular}{|l|l|l|l|}
\hline Results in WarpPLS & Social support & Life Appreciation & Stress Management \\
\hline Social support & - & - & 0.057 \\
\hline Life Appreciation & - & - & $\mathbf{0 . 3 9 3}$ \\
\hline Self Control & - & 0.042 & 0.002 \\
\hline Future Orientation & - & 0.027 & 0.013 \\
\hline Deliberative Thinking & 0.073 & $\mathbf{0 . 0 8 0}$ & 0.073 \\
\hline Age & 0.022 & 0.015 & 0.001 \\
\hline
\end{tabular}

Source: Authors' own research

As Table 9 shows, the most important variable in enhancing stress management is life appreciation, with an effect size of 0.393 that can be qualified as high, and the most effective way of increasing life appreciation is by identifying ways to develop deliberative thinking, with an effect size of 0.08 . Although other paths may work in terms of interventions, and are 
statistically significant, the effect sizes provided by WarpPLS output make clear recommendations regarding the most effective mechanism to be used.

Non-linear relationships. Perhaps one of the most important features provided by WarpPLS, but unavailable either in $\mathrm{R}$ or in other statistical packages, is the capability of capturing non-linear relationships among variables. We selected for discussion two of the most appealing non-linear relationships resulted from our model.

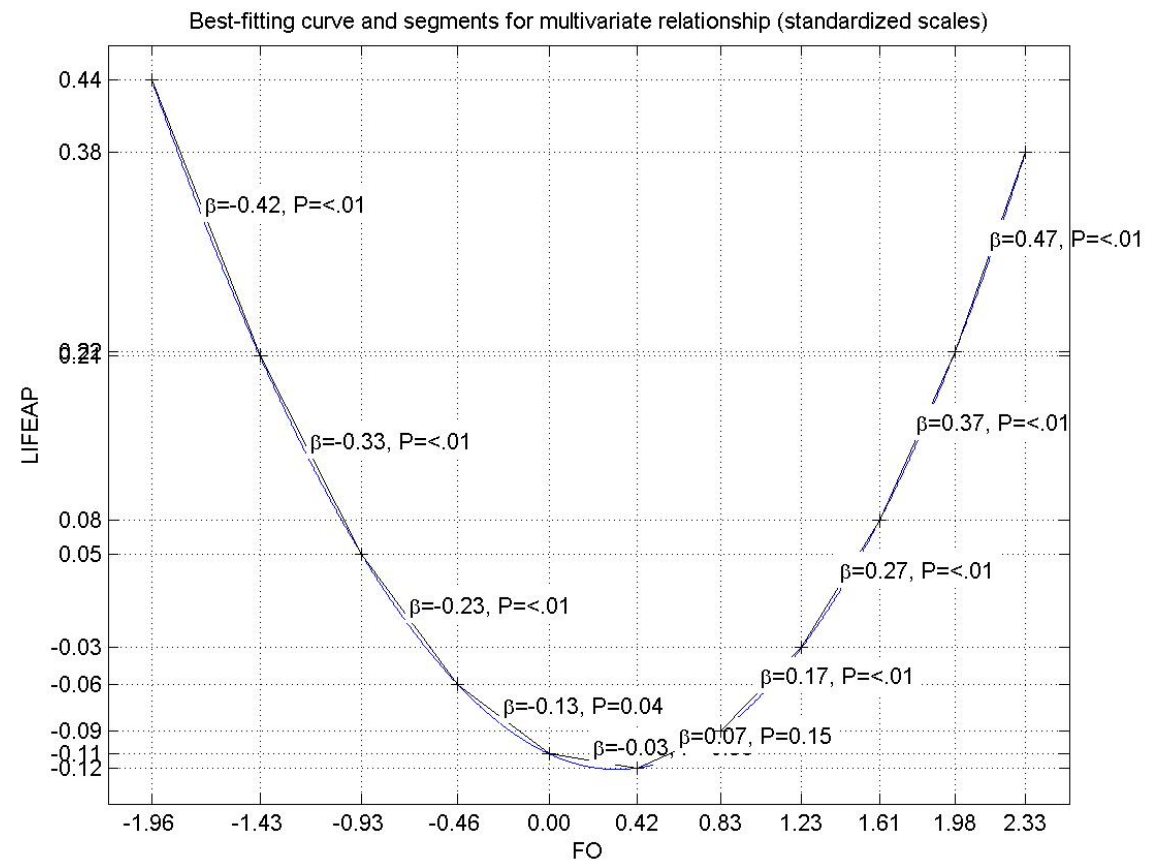

(a)

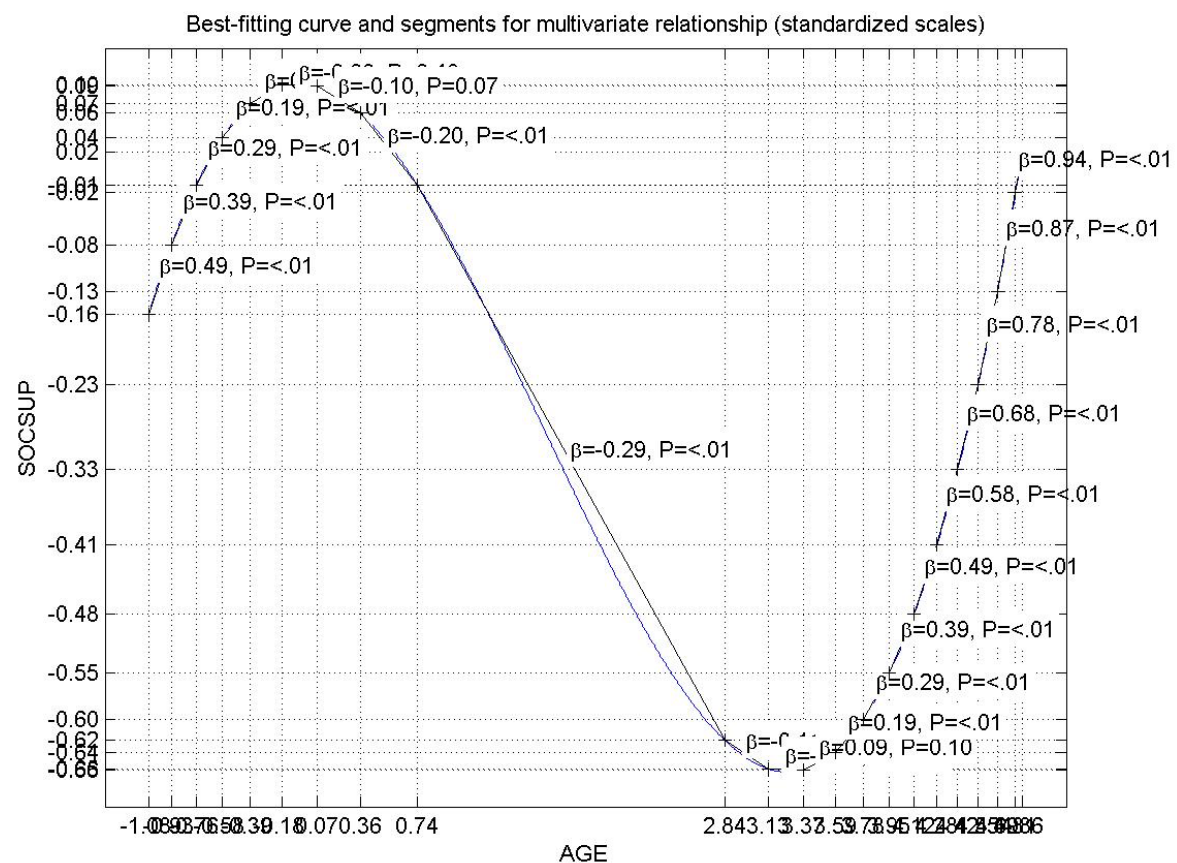

(b)

Figure 2. Examples of non-linear relationships in the model 
Figure 2 illustrates two non-linear relationships resulted from WarpPLS estimation of the model. Future Orientation and Life Appreciation (Figure 2a) describe a U-shaped relationship: in the descending part of the curve, up to the turning point, the more one is preoccupied by the future, the less appreciation one has for life. After orientation toward future goes beyond a certain level ( 0.42 std from mean), it begins to bring positive outcomes, probably based on larger experience and preparedness in enjoying life. It seems that one should accumulate a critical mass in planning/preparing for future before it bears fruit. The relation Age - Social Support is sinusoidally shaped (Figure $2 \mathrm{~b}$ ): very young and especially old aged increasingly depend on support from others, while young adults seem more independent and need less and less social support during their active life. Knowing the precise shape of non-linear relationships has important practical implications in designing the appropriate (and differentiated) policy for each segment of the curve. Ignoring this information and considering the relation insignificant (as it might happen in $\mathrm{R}$ because it implicitly fails to fit a linear relationship over a non-linear one) means to be deprived of a valid policy instrument.

\section{Conclusions and implications}

Our paper presented two parallel estimations of the same variance - based structural model, with the same dataset: one of the estimations is conducted in WarpPLS, and the other one in $\mathrm{R}$, using the "plspm" package. The results revealed several differences: sizeable discrepancies in the values of the loadings, leading to dissimilar composition of the latent variables, different size and significance of path coefficients (beginning with the second decimal), and, most important, disagreement in model validation based on Tenenhaus goodness of fit. In addition, available statistics do not overlap completely, for instance effect sizes are unavailable in R, while WarpPLS does not report eigenvalues, important for assessing block unidimensionality.

Such differences bring into discussion the student - instructor relationship while learning to use (and to trust) specific statistical software. Professors' choice of the software package to be used in class may be guided by software reputation, personal experience or preferences, or mere convenience (if university enjoys a free package from a certain software developer). Since students in statistics usually learn to use various packages, at the same course or at different disciplines, it is likely they will find discrepancies when applying different software to same data, triggering the risk that they might come to distrust software (and statistics) entirely. We believe that students should be made aware of such incongruities, their sources and possible solutions. It is better that they experience such problems in a safe, risk-free environment, such as the classroom, and prepare to deal with them in real-life situations.

Although we cannot provide a general, one-size-fits-all solution, we believe that ultimately the best way of avoiding misleading results is to have a strong theoretical background for the phenomenon under investigation. This can be achieved either by studying the economic (or social, behavioral, etc.) theory that underpins the model, or by asking the experts in the field which results make more sense.

Although the conclusions of our research are limited to the specificities of the particular dataset used here, the differences we found in estimation results are not accidental, but illustrative of a more common and insufficiently acknowledged phenomenon. Since usually we focus on a single package for solving a specific problem, especially for 
teaching purposes, the issue is largely obscured, despite its potentially dangerous implications for accurate decision-making.

\section{References}

Antonides, G., de Groot, I. M., \& van Raaij, W. F. (2011). Mental budgeting and the management of household finance. Journal of Economic Psychology, 32(4), 546-555. https://doi.org/10.1016/j.joep.2011.04.001

Chen, M.-Y., Lai, L.-J., Chen, H.-C., \& Gaete, J. (2014). Development and validation of the short-form adolescent health promotion scale. BMC Public Health, 14. https://doi.org/10.1186/1471-2458-14-1106

Cohen, J. (1988). Statistical power analysis for the behavioral sciences. Hillsdale, NJ: Lawrence Erlbaum.

Cronbach, L. J. (1951). Coefficient alpha and the internal structure of tests. Psychometrika, 16(3), 297-334. https://doi.org/10.1007/BF02310555

Ertz, O., Rey, S. J., \& Joost, S. (2014). The open source dynamics in geospatial research and education. Journal of Spatial Information Science, 8(1), 67-71. https://doi.org/10.5311/JOSIS.2014.8.18

Evermann, J., \& Tate, M. (2016). Assessing the predictive performance of structural equation model estimators. Journal of Business Research, 69(10), 4565-4582. https://doi.org/10.1016/j.jbusres.2016.03.050

Garson, G. D. (2014). Partial Least Squares Regression and Structural Equation Models: 2016 Edition (2016 edition). Statistical Associates Publishers.

Hair, J. F., Sarstedt, M., Ringle, C. M., \& Mena, J. A. (2012). An assessment of the use of partial least squares structural equation modeling in marketing research. Journal of the academy of marketing science, 40(3), 414-433.

Hair, J., Hult, G. T. M., Ringle, C. M., \& Sarstedt, M. (2013). A Primer on Partial Least Squares Structural Equation Modeling (1 edition). Los Angeles: SAGE Publications, Inc.

Keeling, K. B., \& Pavur, R. J. (2007). A comparative study of the reliability of nine statistical software packages. Computational Statistics \& Data Analysis, 51(8), 3811-3831. https://doi.org/10.1016/j.csda.2006.02.013

Kock, N. (2014). Advanced mediating effects tests, multi-group analyses and measurement model assessments in PLS-based SEM. International Journal of e-Collaboration, 10(3), $1-13$.

Kock, N., \& Lynn, G.S. (2012). Lateral collinearity and misleading results in variance-based

SEM: An illustration and recommendations. Journal of the Association for Information

Systems, 13(7), 546-580.

Kuder, G. F., \& Richardson, M. W. (1937). The theory of the estimation of test reliability. Psychometrika, 2(3), 151-160. https://doi.org/10.1007/BF02288391

Lohmöller, J.-B. (1989). Latent Variable Path Modeling with Partial Least Squares. Preluat în din https://www.springer.com/gp/book/9783642525148

McCullough, B. D. (1999). Econometric Software Reliability: EViews, LIMDEP, SHAZAM and TSP. Journal of Applied Econometrics, 14(2), 191-202.

McCullough, B. D. (2010). Econometric Computing with "R". În H. D. Vinod (Ed.), Advances in Social Science Research Using R (pp. 1-21). Springer New York.

Nunnally, J. C., \& Bernstein, I. H. (1994). Psychometric theory (3rd ed.). New York, NY: McGraw-Hill.

Odeh, O. O., Featherstone, A. M., \& Bergtold, J. S. (2010). Reliability Of Statistical Software. American Journal of Agricultural Economics, 92(5), 1472-1489. Preluat în din JSTOR.

Pachur, T., \& Spaar, M. (2015). Domain-specific preferences for intuition and deliberation in decision making. Journal of Applied Research in Memory and Cognition, 4(3), 303311. https://doi.org/10.1016/j.jarmac.2015.07.006

Petras, V., Petrasova, A., Harmon, B., Meentemeyer, R. K., \& Mitasova, H. (2015). Integrating Free and Open Source Solutions into Geospatial Science Education. ISPRS 
International Journal of Geo-Information, 4(2), 942-956. https://doi.org/10.3390/ijgi4020942

Sanchez, G. (2013). PLS path modeling with R. Berkeley: Trowchez Editions, 383, 2013.

Sarstedt, M., Hair, J. F., Ringle, C. M., Thiele, K. O., \& Gudergan, S. P. (2016). Estimation issues with PLS and CBSEM: Where the bias lies! Journal of Business Research, 69(10), 3998-4010. https://doi.org/10.1016/j.jbusres.2016.06.007

Sijtsma K. (2009). On the Use, the Misuse, and the Very Limited Usefulness of Cronbach's Alpha. Psychometrika, 74(1), 107-120. doi:10.1007/s11336-008-9101-0

Shmueli, G., Ray, S., Velasquez Estrada, J. M., \& Chatla, S. B. (2016). The elephant in the room: Predictive performance of PLS models. Journal of Business Research, 69(10), 45524564. https://doi.org/10.1016/j.jbusres.2016.03.049

Strömbäck, C., Lind, T., Skagerlund, K., Västfjäll, D., \& Tinghög, G. (2017). Does self-control predict financial behavior and financial well-being? Journal of Behavioral and Experimental Finance, 14(C), 30-38.

Tangney, J. P., Baumeister, R. F., \& Boone, A. L. (2004). High self-control predicts good adjustment, less pathology, better grades, and interpersonal success. Journal of Personality, 72(2), 271-324.

Tenenhaus, M., Vinzi, V. E., Chatelin Y-M, \& Lauro C. (2005), PLS Path Modeling, Computational Statistics \& Data Analysis, 48 (1), 159-205

Tobias R. D. (1997). An introduction to partial least squares regression. Cary, NC: SAS Institute.

Weibel, R., Bleisch, S., \& Fisler, J. (2012). How open source can help achieving sustainability of e-learning content: The GITTA experience. Proc. Open Source Geospatial Research \& Education Symposium (OGRS), 50-58.

Wold, H. (1975). Path models and latent variables: The NIPALS approach. În Blalock, H. M.; Aganbegian, A.; Borodkin, F. M.; Boudon, R.; \& Capecchi, V., eds. Quantitative sociology: International perspectives on mathematical and statistical modeling. NY: Academic Press.

Yalta, A. T., \& Yalta, A. Y. (2010). Should Economists Use Open Source Software for Doing Research? Computational Economics, 35(4), 371-394. https://doi.org/10.1007/s10614-010-9204-4 